\title{
PSIQUE E INDIVIDUACIÓN: PÉRDIDA Y RECUPERACIÓN DEL SENTIDO DE LA VIDA
}

\section{Psyche and Individuation: loss and recovery of the meaning of life}

\section{Rocío Hernández-Mella}

Profesora investigadora del Área de Ciencias Sociales

y Humanidades. Instituto Tecnológico de Santo

Domingo (INTEC), ORCID: 0000-0002-1331-5453

Correo-e: rocio.hernandez@intec.edu.do

\section{Josefina Gómez-Mena}

Centro Jung Santo Domingo (CJSD). República

Dominicana, ORCID: 0000-0003-2264-2453

\section{Yolanda Santos-Batista}

Centro Jung Santo Domingo (CJSD). República

Dominicana, ORCID: 0000-0002-9866-6016

\section{Recibido: 15/9/2020 • Aprobado: 19/10/2020}

Cómo citar: Hernández-Mella, R., Gómez-Mena, J., \& Santos-Batista, Y. (2020). Psique e individuación: pérdida y recuperación del sentido de la vida. Ciencia y Sociedad, 45(4), 33-47. Doi: https://doi.org/10.22206/cys.2020.v45i4.pp33-47

\section{Resumen}

Este ensayo reflexiona sobre la sensación de vacío que se aprecia a nivel personal y social y propone que se genera en la existencia de un ser humano que carece de un sentido profundo. El ensayo considera que cuando las urgencias de educar la voluntad han disminuido, emerge la profunda necesidad del alma de llevar una vida lejos de lo normal. Este vacío se produce subsumiendo la personalidad a la voluntad, separándole de la fuerza vital, primitiva y natural, a través de una cultura moderna que ha desprendido la fantasía de la existencia El análisis establece que en esta situación es necesario buscar ayuda para comprender el significado de la vida individual o la individuación, y una opción es la terapia analítica de orientación junguiana. Esta, utiliza los sueños para traer a la conciencia los símbolos, figuras y metáforas que habitan en las profundidades de la psique y corresponden a tiempos arcaicos de la humanidad lo cual devuelve el color emocional o la fuerza espiritual a la vida, como lo fue al principio de la vida de cada persona. Desde esta perspectiva, el ensayo argumenta cómo el ser humano encuentra su singularidad en una vida creativa que se expande cuando recupera esa unión primitiva con la naturaleza; reconociendo que, además, al restaurar el misterio en la existencia, la estima propia se reconstruye, así

\begin{abstract}
This essay is a reflection on the sensation of emptiness that is appreciated at a personal and social level and proposes that it is generated due to the existence of a human being who lacks a deep sense. The essay considers that when the urgencies of educating the will have diminished, emerges the deep need of the soul to carry a life far from normal. This emptiness is produced subsuming the personality to the will, separating it from the vital, primitive and natural force, through a modern culture that has detached the fantasy of existence. The analysis establishes that in this situation it is necessary to seek help in understanding the meaning of individual life or individuation, and one option is Jungian analytical therapy. This, uses the dreams to bring to consciousness the symbols, figures and metaphors that dwell in the depths of the psyche and correspond to archaic times of humanity which give back the emotional color or spiritual force to life, as it was at the beginning of the life of each person. From this perspective, the essay argues how human beings find their uniqueness in a creative life that expands when they recover that primitive union with nature; recognizing that by restoring mystery to existence, self-esteem is rebuilt, as well as a sense of renewal. It produce a feeling of immortality, since the
\end{abstract}


como una sensación de renovación produciendo un sentimiento de inmortalidad, puesto que el proceso de individuación no culmina en la autorrealización, sino que fluye desde la psique y permanece en ella.

Palabras clave: alma; psicología analítica; inconsciente; arquetipo; sentido de la vida.

La mente... no puede ser un producto sin historia como no lo es el cuerpo en el que existe.

Carl Jung

\section{Introducción}

Este ensayo obedece a una preocupación por el sentido de la vida. Propone que para comprender cómo cobra significado la existencia humana hay que abordar la psique o alma y sus fuerzas naturales y primitivas alojadas en el inconsciente profundo. Igualmente, considerar el proceso denominado por Jung (2013) como individuación y que consiste en el verdadero desarrollo del ser y su expresión única; para este autor es el modo de hacer conciencia de la humanidad que nos define. El artículo consta de cinco secciones en las cuales se va desarrollando el camino que conduce a una existencia con significado, a partir de los postulados de Carl Gustav Jung, máximo exponente de la Psicología Analítica.

La primera sección denominada mente y simbolo se inicia reconociendo el efecto transformador del símbolo en la mente o entendimiento humano y establece que la palabra está cargada de emoción. El símbolo tiene el poder de evocar eventos que se sitúan fuera de la conciencia, sobre los cuales el razonamiento no posee explicación, mientras que los sueńos se presentan como su fuente más importante. Para Jung (1992, 1995, 2000, 2011, 2012, 2013), las imágenes en los sueños son más vivaces que aquellas provistas por los conceptos, en la experiencia consciente, debido a que se alimentan de lo inconsciente. process of individuation does not culminate in self-realization, but flows from the psyche and remains there.

Keywords: soul; analytical psychology; unconscious; archetypes; meaning of life.

En la segunda sección, pérdida e inconsciente, se establece el consciente y lo inconsciente como los dos estratos que conforman la psique humana, los cuales se encontraban en unión armónica y expresados en la vida cotidiana del ser humano primitivo. Esta psique unitaria aún puede observarse en poblaciones que han logrado preservarse de los embates de la modernidad. Esta ha separado al ser humano de la naturaleza que lo ha engendrado y, endiosando su conciencia, ha expulsado instintos de vida, conjuntamente con su expresión simbólica arquetípica, hacia lo profundo de la psique, para ignorarlos. Establece Jung (1995) que la modernidad ha despojado de los adornos de la fantasía al lenguaje, los números y el pensamiento; al punto que las piedras, el agua, la tierra y el aire ya no poseen voz propia. Al separarse el ser humano de la naturaleza ha perdido la fuerza emotiva que esas relaciones simbólicas proporcionaban en su origen.

La tercera sección, psique y arquetipos, muestra que el misterio perdido de los símbolos se encuentra en lo inconsciente; en esa parte de la psique que es tan profunda que resulta arcaica y universal. El inconsciente arcaico produce imágenes primordiales que se hacen presente al colectivo humano en sueńos, fantasías, visiones, ensońaciones y que Jung (1995) llamó arquetipos.

Individuación y recuperación es la cuarta sección del trabajo. Por medio a la individuación es posible recomponer la psique fraccionada, consiguiendo cada persona su verdadero desarrollo individual, único, con lo cual su vida va "recuperando" un sentido profundo y, como tal, significativo. Jung (2013) expone que 
por medio a la individuación la psique logra obtener una diferenciación que deviene liberadora, al salvar a la persona de quedar sumergida en una comunidad informe.

La quinta y última sección se designa sentido de la vida. Dada la reunificación de lo inconsciente junto a la conciencia, al interno de la psique surge el sí-mismo, de acuerdo a Jung (citado en Jaffe, 1995), o sea, una personalidad nueva con un sentido de sí vivificado que está consciente de su destino y ha recuperado la esencia númine o espiritual que posee la realidad. Es cuando el existir se convierte en una verdad espiritual.

\section{Mente y símbolo}

El símbolo es una representación como resultado de la creación de una realidad mental, es decir, cuando una aprehensión del mundo por medio a los sentidos queda transformada en imagen y significado. Vale decir que la producción de símbolos deriva en una función psicológica de gran importancia de la mente humana. Piaget (1975, 1986; Coll, 2012) reconoce que cuando la conciencia empieza a producir símbolos, mediadores entre el entendimiento y los objetos del mundo, el infante se hace capaz de imaginar; en tanto que Vygotsky (1979, 2010; Karpov, 2006) explica que el o la bebé nace en un mundo nombrado y que las primeras palabras, pensadas y utilizadas para llamar la atención sobre un objeto, son verdaderas obras de arte, cargadas como están de significado y emoción (Hernández-Mella \& Pacheco-Salazar, 2017).

Igualmente, Jung (1995) señala la importancia de la función simbólica; en esta oportunidad resaltando eventos y circunstancias que se sitúan fuera del alcance del entendimiento humano: "cuando la mente explora el símbolo, se ve llevada a ideas que yacen más allá del alcance de su razón: (Jung, 1995, p. 20). El símbolo hace posible acceder a ellas, es decir, percatarse de su presencia e influjo en la vida de las personas. Para este autor, existe una "imagen primera" la cual remite a un inconsciente colectivo concebido como "fenómeno de primera mano" que guarda la imagen primordial del mundo (Jung, 2012, p. 146). A deferencia de Freud (2000), para quien el inconsciente se formaba con los contenidos reprimidos por la conciencia, Jung (1992, 2000) postulaba que la mente o psique nace como un hecho inconsciente, donde no se reconocen los opuestos hasta que, poco a poco, se produce la diferenciación y con ella la conciencia.

La mente consciente puede explorar el símbolo, pero ha de admitir que este no quedará explicado del todo, con su razonamiento. El conocimiento que se logra a partir de un esfuerzo consciente no puede rebasar ciertos límites impuestos por la estructura y calidad de funcionamiento de los sentidos o el uso de instrumentos dedicados a compensarlos. Expone Jung (1995) que:

(...) aun cuando nuestros sentidos reaccionan ante fenómenos reales, visuales y sonoros, son trasladados en cierto modo desde el reino de la realidad al de la mente. Dentro de la mente, se convierten en sucesos psíquicos cuya naturaleza última no puede conocerse (porque la psique no puede conocer su propia sustancia psíquica) (pp. 21, 23).

Para nuestro propio beneficio, la mente o psique está preparada para producir símbolos inconsciente y espontáneamente en forma de sueños. Por tal motivo, los sueños son la fuente más recurrida y universalmente utilizada al investigar la facultad simbolizadora del ser humano.

Los sueños logran tener una estructura definida que apunta hacia una idea y posee una intención subyacente; sin embargo, esto último no se comprende de forma inmediata. De ahí surge la necesidad de interpretar el sentido de los sueños. Jung (1995) demanda concentrarse en las asociaciones que sugiere la propia actividad onírica. Esto es, para entender un sueño hay que examinarlo en 
todos sus aspectos "al igual que se puede coger en las manos un objeto desconocido y darle vueltas... hasta que se conocen los detalles de su forma" (Jung, 1995, p. 28).

La explicación anterior permite visualizar lo que Jung (1995) considera ser su método de interpretación de los sueños, y que el propio autor equipara a "una circunvalación" (p. 29) que posee en su centro las imágenes específicas del sueño. Estas imágenes son mucho más pintorescas y vivaces que los conceptos extraídos de la experiencia en el mundo real, cuando se está despierto, y Jung (1995) resalta que ocurre porque en el sueńo los conceptos se alimentan de un significado inconsciente.

Desafortunadamente, la experiencia onírica no resulta ser únicamente positiva. En palabras de Jung (1995):

Por desgracia los sueños son difíciles de entender (...) tienen (..) imágenes que parecen contradictorias y ridículas [que] se apiñan sobre el soñante, se pierde el normal sentido del tiempo y las cosas corrientes pueden asumir un aspecto fascinante $o$ amenazador (...) la persona corriente se inclina a desentenderse de ellos o a confesar que se siente confusa (p. 39).

Según Jung (2012), los sueños no se limitan a aparecer al dormir; siguen expresándose durante la vigilia - ya que poseen vida propia - solo que sin alcanzar el nivel de la conciencia. Puede ocurrir, sin embargo, que la persona atisbe su presencia en forma de ensońaciones. Ciertamente, la vida nocturna e incluso diurna se encuentra plena de imágenes mudas, quietas, que aguardan ser invitadas a cantar o danzar, retornando el misterio a su espacio propio y encontrado desde el origen de la existencia (Hernández-Mella, et al., 2017; Hernández-Mella et al., 2019).

\section{Pérdida e inconsciente}

El vacio es insoportable en un estado de libertad plena. La tarea paradojal de la conciencia es resolver la contradicción entre la vigilia que nos mata día a dia y el sueño donde se diluyen todas las ansiedades.

\section{Rubén Camacho}

Los sueños ocupan el lugar donde antes había reguladores colectivos, que Jung (2013) identifica como viejas ideas y costumbres relacionadas con el comportamiento moral. Para el autor, estos reguladores poseían la función de vincular la vida con lo inconsciente, lo cual posibilitaba hallar un sentido a dicha existencia. Pues bien, estos puentes que servían para conectar al ser humano originario o "primitivo" con sus antepasados "se han desmoronado, al menos en parte" (p. 124). Tal desvinculación con las raíces primarias genera un sentimiento de pérdida que trae inseguridad con respecto a los valores a seguir.

En la antigüedad, los individuos se sentían muy seguros de poseer lo que modernamente se reconoce como valores internos y externos, ya que ellos no establecían diferencia entre los dos tipos. Tal diferenciación se generó en la conciencia, al momento en que la mente se separó de la vida para "observarla” en vez de vivirla. Esta disociación, si bien en el pasado fue necesaria para el desarrollo de la conciencia, hoy no debe permanecer inamovible, establece Jung (2013); en cambio, enfatiza que es preciso hacer un doble esfuerzo, al lograr una participación plena en la vida y dejar convocado lo inconsciente como complemento.

La explicación que ofrece Jung (2013) demanda recobrar una visión de mundo creada por la mente humana en épocas pasadas y encontrar su pertinencia en la existencia del ser humano moderno. Del mismo modo, Piaget y García (1984) encuentran valor al establecer un paralelo entre el desarrollo del pensamiento científico a lo largo de la 
historia, principalmente dentro de las matemáticas y la ciencia de la mecánica, con la psicogénesis de la conciencia, a lo largo de la vida, establecida en diferentes etapas durante su evolución. Las explicaciones de ciertos fenómenos que ofrecen infantes y adolescentes son comparables a aquellas de grandes filósofos y pensadores de la antigüedad, aportando los autores citados coincidencias altamente sorprendentes (un niño de ocho años describe la trayectoria de un proyectil de la misma manera que lo hacía Aristóteles y posee un concepto de fuerza muy próximo al manejado en el siglo xIv). Conocimiento y valores logrados a lo largo de la historia de la humanidad no han desaparecido, sino que la conciencia los ha perdido de vista en su proceso de diferenciación de lo inconsciente.

Por lo tanto, en la psique existen niveles que hacen referencia al ser consciente y a lo inconsciente. A este respecto, el reclamo de Jung (2013) se orienta a recuperar un vivir —en estado consciente- unido significativamente a formas arcaicas - mantenidas en lo inconsciente- apreciadas como válidas y como fuente de conocimiento. De este modo, se logra una vivacidad y colorido renovados en la existencia, perdidos al entrar en vigencia las "leyes" de la modernidad, pero hallados a lo interno de la psique (Hernández-Mella et al., 2020).

De vuelta al paralelismo, se destaca la fuerza de la imaginación en la mente infantil, tal y como propone Piaget (1986), sobre todo en el surgimiento de la etapa simbólica. En ella, el entendimiento se transforma en pensamiento y de la aprehensión (comprensión) de los objetos "reales", tal y como ocurría al nacer, se evoluciona construyendo un mundo imaginado; irrumpe la fantasía que consigue potenciar la belleza de lo que le rodea. En esta etapa de la existencia, el infante no hace diferencia entre su mundo interno y el externo, tal y como ha manifestado Jung (2013) que ocurría en la antigüedad y permanece en poblaciones originarias que perviven.
El ingreso a la modernidad queda marcado con una pérdida en la vida social, según Jung (1995), lo mismo que en la personal; puesto que el ser humano ha "(...) aprendido a prescindir de los adornos de la fantasía en el lenguaje y en los pensamientos" (p. 45). Si nos fijamos atentamente, cada palabra posee un significado ligeramente diferente en cada persona, aun entre individuos que comparten un mismo entorno y cultura; pero esa diversidad queda anulada con la definición "de diccionario", obligatoria a nivel social (imprescindible en una tesis doctoral, por ejemplo, aunque no en la poesía, salvadora). Igual ha sucedido con los números, que se considera el signo más objetivo que existe:

Los mismos números que utilizamos al contar son más de lo que pensamos que son. Son, al mismo tiempo, elementos mitológicos (para los pitagóricos eran, incluso, divinos); pero no nos damos cuenta de eso cuando utilizamos los números con un fin práctico (Jung, 1995, p. 40).

Es posible trasponer la pérdida histórica a la psicogénesis, estableciendo que una de las manifestaciones de la mente consciente que ha logrado "madurez", para Piaget (1986), es la utilización de la lógica como estrategia de razonamiento en la producción de conocimiento acerca del mundo. En sus inicios, se expresa como una lógica de ordenamiento de los objetos en el mundo; por ejemplo, poder colocarlos por tamaño, del más grande al más pequeño o viceversa (sin destacar aquello que había atrapado la admiración infantil). En una etapa posterior, la mente razona a partir de ideas o pensamiento abstracto, que equivale a despojar aún más los objetos de sus cualidades "particulares", para agruparlos por unas características "generales" que no les pertenecen (hay 5 naranjas que convertimos en 1, 2, 3, 4 y 5 objetos, atribuyendo el 1 a cualquiera de ellas; ¿dónde quedan el colorido que destaca en cada una, su particular olor o textura, tal y como apreciaba la mente infantil?). 
Otra de las pérdidas corresponde a lo que Jung (2012) manifiesta como la "inmanencia de pensamiento", que solía ser aceptado en la antigüedad y se ha perdido en la actualidad "de forma extendida" (p. 82). El autor se refiere a la visión de que los pensamientos "llegan" a la mente de manera directa o inmediata, revelando que poseen una libertad que la voluntad humana es incapaz de controlar. Jung (2012) encuentra que se persiste en la ilusión de que la persona es quien produce su pensamiento, en vez de aceptar que son "seres originales que caminan por doquier en el cerebro" (p. 82, traducción ajustada):

(...) el hecho es que [el humano] está atrapado en su propia piel, y, por ello, su pensar siempre se encuentra influido por la naturaleza en formas que él no controla totalmente. Lo inconsciente tiene el poder de influir nuestro pensar de maneras increíbles (p. 82-83, traducción ajustada).

Lo inconsciente proviene de la naturaleza Es posible seguir el rastro de la naturaleza hasta el momento histórico cuando el ser humano se dispuso dejar las huellas de sus pies o sus manos en lodo o al presionar cenizas sobre rocas, alumbrando la primera escritura (Abram, 1997).

Los símbolos nacientes representaron la simbiosis ser humano-naturaleza a tal punto, que llevan a Abram (1997) a proclamar que:

Todo sistema de escritura antigua de nuestra especie permanece atado a los misterios de un mundo más-allá-de-lo-humano (...) En rocas (...) y paredes de cuevas [las] figuras se entremezclan con formas humanas, o parcialmente humana y parcialmente Otra (parte insecto, búho o alce) (p. 96, traducción ajustada).

Posteriormente, sistemas pictográficos como los jeroglíficos egipcios o también aquellos encontrados en China y en Mesoamérica incluyen carac- teres llamados "ideogramas" por los expertos, pues se trata de un carácter pictórico que no se refiere exactamente a la entidad que pretende plasmar, sino a una cualidad de ella o a otro fenómeno asociado con esa entidad.

Finalmente, la evolución de estos sistemas primarios de escritura se produjo con el cambio de la participación sensorial "lejos del paisaje circundante" (Abram, 1997, p. 97, traducción ajustada) hacia imágenes propiamente humanas, logrado en aras de la eficacia de la misma. Sin embargo, los "glifos" que constituyen el grueso de estas escrituras antiguas "recuerdan continuamente al cuerpo lector su procedencia de un más-que-humano campo de significados" (Abram, 1997, p. 97, traducción ajustada).

Los animales, las plantas y los elementos naturales fueron perdiendo poco a poco sus voces con cada una de las transformaciones sufridas por la escritura antigua. Esta termina convertida en alfabeto griego, completamente desposeído de la referencia al mundo natural al que estaba asociado (Abram, 1997). Así, pierde su vínculo con la naturaleza una buena parte del pensar y el sentir en el género humano.

Jung (1995) lamenta el hecho de que la mayoría de las personas han transferido al inconsciente todas las "asociaciones psíquicas fantásticas" (p. 45) que posee todo objeto o idea, las cuales provenían directamente del mundo natural, hermoseado por la psique primitiva. Con su racionalismo, el individuo moderno "se siente aislado en el cosmos, porque ya no se siente inmerso en la naturaleza y ha perdido su emotiva 'identidad inconsciente' con los fenómenos naturales” (p. 95).

Al separarse de la naturaleza, el ser humano ha perdido la fuerza emotiva que proporcionaban esas relaciones simbólicas; ha perdido el misterio que presentan los símbolos. Para las poblaciones originarias la imagen de la Gran Madre poseía un 
significado profundamente emotivo que no está presente en el concepto de "materia". Por igual, lo que era el espíritu se identificaba con el Padre de Todo, pero su inmensa energía emotiva se disipa en el concepto de "intelecto".

El escritor italiano Salvatore Quasimodo (2007) expresa metafóricamente la pérdida en su poema:

\section{$Y$ enseguida anochece:}

Cada uno está solo

sobre el corazón de la tierra,

traspasado por un rayo de sol,

y enseguida anochece

Ya nada se considera sagrado o como se lamenta Jung (1995): "hemos desposeído todas las cosas de su misterio y su numinosidad" (p. 94) o energía psíquica. Los antropólogos han descrito lo que sucede cuando una sociedad originaria ha perdido sus valores espirituales al entrar en contacto con la modernidad, expone el autor, y es que su gente pierde el sentido de la vida, además de que su organización social desaparece "y la propia gente decae moralmente” (Jung, 1995, p. 94).

Por fortuna, esta pérdida es sentida solo al nivel de la conciencia, mientras en lo inconsciente se encuentra todo un mundo lleno de colorido y de fuerza emotiva capaz de otorgar sentido a la vida cuando es recreado en la existencia cotidiana.

\section{Psique y arquetipos}

... to the primitive, life is far more voluminous than to us, because there is not only the thing but also its meaning

Carl Jung

Puede ser que nos encontremos hoy en búsqueda de esos valores sagrados que vivifiquen la vida, en lugar de que la eficienticen. Por tal razón, se propone como válido el recurrir a la psicología de lo inconsciente, ya que aporta el conocimiento derivado del estudio de las figuras psíquicas o imágenes que aparecen en sueños, fantasías, visiones y delirios. Si tomamos como ejemplo la psique de las poblaciones originarias o primitivas, advierte Jung (2012) que muestra una psicología mucho más balanceada que la del ser humano moderno; la razón de esto es que dichas poblaciones no poseen objeción alguna en dejar que lo irracional o inconsciente se haga presente en sus vidas, mientras que nosotros lo resentimos.

Entre los pueblos originarios el "alma" o psique no se considera unitaria, revela Jung (1995); lo que significa que ellos suponen que comparte la existencia con un "alma selvática", encarnada en un animal salvaje o en un árbol, con el cual el humano posee una especie de identidad psíquica. Para nombrar este proceso simbiótico de almas, Jung (1995) adopta el concepto de participación mistica, originalmente utilizado por el etnólogo francés Lucien Levy-Brühl (citado en Jung, 1995). Una ofensa contra el alma selvática se interpreta como una ofensa contra el individuo cuya mutua identidad los une.

De ahí que cuando los "conceptos instintivos" inconscientes surgen en la mente primitiva, la conciencia los integra en un esquema psíquico coherente, a través de símbolos numínicos o llenos de energía emotiva y comúnmente considerados sagrados. Lo importante para Jung (1995) es rescatar que la mente primitiva reconoce esas propiedades psíquicas vivificantes con las cuales dota a animales, plantas o piedras. Atribuye a todos ellos poderes que resultan extraños e inaceptables para una mente moderna.

Pues bien, esas asociaciones primitivas -que evocan los orígenes simbióticos ser humano-naturaleza - no han desaparecido, sino que se hallan presentes en lo inconsciente. Un tipo de inconsciente más profundo que el inconsciente personal, 
descrito por Freud $(1991,2000)$ y que Jung $(1992$, 2000) denomina colectivo porque se encuentra en toda la humanidad.

Jung (1995) adjudica el adjetivo de arcaica a la imagen que guarda el inconsciente colectivo, recreando el concepto utilizado por Freud (1991, 2000). Este último autor mantuvo que ese tipo de imagen resultaba de "remanentes" psíquicos de épocas pasadas; en cambio, para Jung (1995), esas imágenes arcaicas son parte integrante de lo inconsciente y surgen en los sueńos y visiones de todas las personas. El autor expresa que las imágenes arcaicas:

(...) pueden observarse en todas partes, tanto si el soñante es culto, como analfabeto, inteligente o estúpido. [Las imágenes arcaicas] siguen funcionando $\mathrm{y}$ son especialmente valiosas precisamente a causa de su naturaleza histórica (Jung, 1995, p. 49).

Las imágenes arcaicas son las que hacen posible restaurar el puente (roto y perdido al entrar en la modernidad) que comunica las expresiones del pensamiento consciente con las formas inconscientes de origen primitivo, invocando su fuerza emotiva. Esto permite ver el mundo y lo humano unidos, concebidos como naturaleza, y gracias a esta unión recuperar todo el colorido y peculiaridad de lo vivo (Hernández-Mella et al., 2020).

¿Cuál sería el valor que trae consigo esta recuperación de la naturaleza? En principio, un sentido de respeto y protección hacia todo lo vivo, reconociendo como un dolor propio las heridas infligidas a todo lo natural. Y un sentimiento de pertenencia que aprueba encauzar la existencia por caminos más acordes con la individualidad de cada quien.

Sueños y ensoñaciones traen a la existencia su naturaleza originaria; esto es, sus instintos y pensamientos peculiares. Los instintos componen "los profundos estratos (...) de la psique humana"
(Jung, 1995 p. 52). Su carácter es simbólico, siendo los símbolos oníricos los mensajeros por excelencia de esa parte profunda e inconsciente hacia la parte racional de la mente humana. Ambas partes del ser humano, su conciencia en donde reside lo racional y su psique irracional, conforman y determinan su vida. Por la conciencia se entera de la existencia del mundo y por la psique puede conocerlo, que para Jung (2013) significa entrar en contacto con la imagen psíquica.

Esas imágenes primordiales identificadas por Jung (1995) comprenden gestos que son entendidos universalmente, formas de pensamiento y actitudes que "siguen un modelo que se estableció mucho antes de que [el ser humano] desarrollara una conciencia reflexionadora” (p. 76).

Ese modelo inconsciente se expresa en maneras más o menos personales; sin embargo, su forma es general y abarca el colectivo humano universal, además de ser encontrado en todo tiempo. Se trata de modelos de la psique humana que son innatos y heredados, los cuales Jung (1995) denominó arquetipos.

El arquetipo tiene que ver con una tendencia a formar representaciones o símbolos, la cual es tan marcada que, según Jung (1995), se equipara "al impulso de las aves a construir nidos o el de las hormigas a construir colonias organizadas" (p. 68). El origen de los arquetipos es tan antiguo que no es posible precisarlo. Lo que sí es evidente es su efecto inevitable en la psique humana. Jung (1995) se pregunta "¿por qué habríamos de suponer que el hombre es el único ser viviente desprovisto de instintos específicos o que su psique está vacía de todo rastro de evolución?”, defiende Jung (p. 75).

En este punto se precisa diferenciar lo que es el instinto básico con respecto al arquetipo. El primero alude a necesidades fisiológicas que son percibidas por los sentidos, mientras que Jung (1995) establece que, al mismo tiempo, también se 
manifiestan en forma de fantasías, cuya presencia es revelada por medio de representaciones simbólicas. Estas manifestaciones son los arquetipos. Los arquetipos son factores dinámicos y se manifiestan espontáneamente, tal como lo hacen los instintos.

Para Jung (2013), los arquetipos son imágenes simbólicas:

(...) sobre las que el espíritu humano se ha construido y diferenciado (...) [corresponden a] visiones primigenias generalísimas del espíritu primitivo que nunca designan contenidos especiales, sino que son significativas por la riqueza de su contenido. LévyBruhl las llama représentations collectives; Hubert y Mauss "categorías a priori" de la fantasía (p. 16-17).

Debido a su origen antiguo, los contenidos arquetípicos no pueden ser asimilados echando mano de ideas filosóficas o religiosas disponibles; el simbolismo arcaico de sus figuras típicas se aviene más al que aparece en los mitos y en los cuentos infantiles que no tienen edad. Del mismo modo, Jung (2013) reconoce esas formas arquetipicas en la teoría de la alquimia y las define como "configuraciones puras de la fantasía" que, además de presentarse en mitos y cuentos, se llegan a conocer por los "sueños, visiones y delirios de individuos concretos" (p. 301).

Lo primero a destacar es el carácter autónomo de las fantasías ligadas al arquetipo. Jung (2013) nos advierte del error que se comete al pensar que han sido creadas por las personas:

[cuando] en realidad las fantasías han caído sobre ellas. La involuntariedad ya no se puede negar cuando el fragmento de fantasía adopta, cosa que no es rara, un carácter obsesivo, como por ejemplo las melodías que no se le van a uno de la cabeza, las ideas fóbicas o los llamados "tics simbólicos" (Jung, 2013, p. 15).
La fantasía es la expresión normal de la psique o como bien lo expresa Jung (2013) "es la espontaneidad del alma" (p. 60), que surge cuando la conciencia relaja su control o cuando este desaparece, como ocurre al dormir, dando lugar al sueño. Para el autor, la conciencia representa el lado diurno de la psique, mientras que su lado nocturno corresponde al funcionamiento inconsciente.

Los sueños estudiados en serie hacen posible que se identifiquen motivos, que son figuras que se repiten con ciertas variaciones y conciernen a personas, animales, objetos, situaciones. Obedecen a un impulso vital que desencadena un proceso que, al volverse consciente, al menos de forma parcial, da origen a una serie de imágenes.

Así como ocurre en sueños, sucede en las visiones y delirios en los cuales encontramos las fantasías como una manifestación de la actividad anímica inconsciente. Estas fantasías describen la situación interior de la persona y se trata de una realidad que no es reconocida por la conciencia o que lo hace "de mala gana", señala Jung (2013, p. 142) (Hernández-Mella et al., 2017; Hernández-Mella et al., 2019).

Si bien hay sueños que exponen deseos o miedos cumplidos, hay otros que son anticipatorios $y$ existen muchos tipos más. "No debemos olvidar una cosa: casi la mitad de nuestra vida tiene lugar en un estado más o menos inconsciente (...) es muy probable que nuestra alma sońante disponga de una riqueza de posibilidades de contenido (...)" (Jung, 2013, pp. 146 y 147).

Las imágenes arcaicas o arquetipos que surgen en los sueños, fantasías, visiones y delirios posibilitan restablecer el vínculo entre el pensamiento consciente moderno y las formas inconscientes de origen primitivo, permitiendo ver la unión mundo-ser humano. Esta fusión restaura esa imagen primordial que nos devuelve a la naturaleza y que unifica la psique, tal y como aparece al inicio de toda vida. 
El ir logrando complementar la conciencia con lo inconsciente requiere de un proceso terapéutico analítico durante el cual la persona irá reconociendo quien verdaderamente es y que Jung (2013) denominó individuación.

\section{Individuación y recuperación}

\section{El paciente aceptará su neurosis porque habrá comprendido el sentido de su enfermedad}

Carl Jung

Individuación es el proceso que Jung (2013) reconoce como el verdadero desarrollo humano individual, durante el cual lo inconsciente se sitúa en el primer plano de interés. Las imágenes surgidas de ese estrato profundo de la psique evocan figuras mitológicas, por lo que se asume que la significación en el desarrollo psíquico individual se encuentra en un pasado remoto. Esa presunta regresión produce temor a no pocas personas, advierte Jung (2013):

El asunto se vuelve especialmente peligroso cuando se deja al descubierto la capa mitológica de la psique, pues estos contenidos suelen ejercer una fascinación asombrosa (...) lo cual permite comprender la formidable influencia de las representaciones míticas sobre la Humanidad. Es como si (...) las representaciones míticas, con su peculiar simbolismo, [llegaran] a las profundidades del alma humana (...) a subsuelos históricos a los que nuestra razón, la voluntad y la buena intención no llegan jamás (...) (p. 19).

Por oposición a lo expuesto, Jung (2013) considera que, más que una regresión, la individuación propone un "reculer pour mieux sauter" (p. 19) o dar un paso hacia atrás y tomar impulso para saltar; es decir, reunir fuerzas que al integrarlas entre sí producen un nuevo orden psíquico. Se trata de incluir imágenes arcaicas como parte de la vida consciente personal, posibilitando una existencia más colorida y llena de fuerza emotiva.

Por medio a la individuación, la psique obtiene una diferenciación que resulta liberadora, pues se salva de quedar sumergida en la "inconsciencia de la mera comunidad" (Jung, 2013, p. 59). Esto se logra a partir de un proceso analítico, en la medida que la persona permite que las figuras de su inconsciente colectivo animen su existencia, consiguiendo una interpretación con significado propio (Hernández-Mella, Liranzo-Soto y Castillo, 2015).

En el análisis animado por el psicoterapeuta, se busca lograr un estado de contemplación del objeto que emerge del inconsciente, hasta obtener "la aparición esporádica de 'huellas crepusculares' de representaciones", explica Jung (2013, p. 63). Consiste en el paciente identificar imágenes o sentimientos a través de esa mirada interior compasiva. El autor reconoce que, de este modo, vuelve lo que se encuentra reprimido o perdido en los estratos profundos del ser, si bien convertido en una sombra:

Esto ya es un beneficio, aunque a veces sea penoso, pues lo inferior e incluso lo reprobable me pertenece y me da esencia y cuerpo, es mi sombra. ¿Cómo puedo ser esencial sin arrojar una sombra? También lo oscuro pertenece a mi totalidad; $y$ al volverme consciente de mi sombra recupero también el recuerdo de que soy un ser humano como todos los demás (Jung, 2013, p. 63).

El proceso analítico o de terapia junguiana queda convertido en un espacio de oportunidades de transformación. Iniciado a partir del reconocimiento de los contenidos reprimidos y seguido por el esclarecimiento del valor que poseen para la vida del ser humano particular, llega el momento en que las personalidades del paciente y el analista se combinan, originando un verdadero cambio en ambos individuos. Esto ocurre debido a los factores irracionales que surgen en la terapia; de ahí que Jung (2013) admita que la psicoterapia es un arte que requiere 
del involucramiento de todo el ser del analista (Hernández-Mella et al., 2015; Hernández-Mella et al., 2017; Hernández-Mella et al., 2019).

La fase de transformación ocurre con la terapia en el momento en que la psique del paciente empieza a demandar algo más de la vida; cuando el individuo se da cuenta que no se conforma con ser un ente social adaptado a la normalidad imperante en su entorno. Jung (2013) explica que es el momento en que se hace patente la necesidad más profunda del alma de "poder llevar una vida anormal" (p. 73), entendiendo por esta afirmación llevar una vida diferenciada, particular. Desplegar la creatividad que traen consigo las imágenes arcaicas del inconsciente, recuperando para la existencia una fuerza afectiva y un colorido perdidos.

Es necesario precisar que una transformación como la descrita podrá generarse solamente cuando se haya depuesto la sobrevaloración de la conciencia. Esta actitud es más proclive en las personas que se encuentran en lo que Jung (2013) denomina la segunda mitad de la vida. En esta etapa, la educación de la voluntad no es lo importante, sino "comprender el sentido de su vida individual, para lo cual precisa de la experiencia del propio ser (...) esta persona siente su actividad creativa (...) como un trabajo y como una buena obra en sí misma" (Jung, 2013, p. 54).

Por otro lado, el arribo del momento de la transformación hace necesaria la discusión en torno a lo que paciente y analista consideran su cosmovisión, forzada por la irrupción de la potencia irracional de lo inconsciente. Es decir, el análisis en la terapia no se reduce a lo físico o al funcionamiento fisiológico; al recurrir a la psique y concebirla con las propiedades del alma, Jung (2013) reconoce la dominancia de ella sobre el cuerpo y en el trabajo terapéutico una gran complejidad. La cosmovisión otorga el sentido a la terapia analítica y Jung (2013) no oculta su deseo de que los terapeutas valoren convertirse en "medio filósofos" (p. 82).
El énfasis filosófico en la labor terapéutica conduce al autor hacia asumir el sufrimiento como parte de la existencia, defendiendo que "sufrir no es una enfermedad, sino el polo contrario normal de la felicidad" (Jung, 2013, p. 81) (Hernández-Mella et al., 2015). Además, evidencia la necesidad de recurrir a la escuela de los filósofos médicos del pasado remoto, tiempo en el cual el cuerpo no estaba separado del alma:

(...) su meta [de la psicoterapia] (...) es tomar en cuenta por igual el factor fisiológico y el factor espiritual (...) nuestra psicoterapia traslada su método empírico objetivo a la fenomenología del espíritu (Jung, 2013, p. 86).

Individuación es el proceso por medio del cual la persona logra un desarrollo verdadero, puesto que la psique, al diferenciarse de lo aceptado como normal, va permitiendo que las figuras mitológicas surgidas del inconsciente colectivo animen (den alma) su cotidianidad.

La individuación es el resultado de una terapia analítica junguiana en la que, al recuperar los contenidos perdidos en lo inconsciente, la vida de la persona recobra su sentido profundo e individual y se vuelve creativa.

\section{Sentido de la vida}

...el sentido y el sinsentido son parte de la plenitud de la vida

Carl Jung

¿A qué corresponde el sentido de la vida? Como toda pregunta metafísica, una contestación positiva, así como una negativa, podrán ser válidas o aceptadas, considera Jung (en Jaffe, 1995). Cada respuesta constituye la creación de un mito, un aporte propio a aquello que no posee una respuesta. Lo que es cierto para Jung (2013) aparece en la psiconeurosis $y$ es el sufrimiento, que ocurre cuando el alma no 
ha descubierto su sentido y posee una sensación de vacío religioso.

En la actualidad, la condición humana se encuentra luchando por lograr la reunificación de los opuestos, que revela su deseo de unificar expresiones de sí misma que se encuentran separadas entre sí. Como bien expone Jaffe (1995), siguiendo a Jung, a pesar de todo el conocimiento acumulado, el mundo se escinde en dicotomías ideológicas y el individuo sufre de disociación psíquica. Es lo que Jung (2013) ha reconocido como la neurosis general de estos tiempos, proveniente de un sentido de futilidad que se extiende cada vez más. Jung (2013) advierte al individuo moderno sobre el peligro que acarrea la pérdida del alma, su ser particular, diferenciado, puesto que lo despoja de su humanidad (Hernández-Mella et al., 2020).

La terapia analítica provee un camino individual de curación, que consiste en la integración de elementos del inconsciente arcaico en la conciencia. El estar la conciencia aferrada a una actitud unilateral de existencia produce una disposición neurótica que el psicoterapeuta procura equilibrar; acompańa al paciente a identificar en sus sueños $\mathrm{y}$ visiones esos contenidos complementarios que equilibren su mente. Las experiencias personales conscientes unidas a ese ámbito oculto, más allá del mundo tangible, ubicado en el inconsciente colectivo arcaico, aportan tiempo y un sentido de eternidad a la vida.

El inconsciente colectivo trae consigo a la consciencia una "sensación de renovación de vida para la cual no hay final (...) de este modo, cuando alcanzamos la realización (...), con ella viene el sentimiento de inmortalidad" (Jung, 2012, p. 154, traducción ajustada). El proceso de individuación no culmina cuando se ha logrado una existencia en plenitud, ni se reduce a una comprensión intelectual de la misma, sino que aporta un sentido y este fluye de la cualidad numinosa o energética que emana de lo profundo de la psique (Hernández-Mella et al., 2015).

Los símbolos que son propios del proceso de individuación, expresados en la terapia, son el círculo y la cuaternidad. Estos vienen representados en los sueños del mismo Jung (2013) como de sus pacientes "desde hace mucho tiempo como un mandala cuadripartito" (p. 220). Esos símbolos remontan la psique hacia atrás, a un tiempo histórico en el cual las sociedades se encontraban a un nivel primitivo; igualmente, la hacen mirar hacia adelante, "a un orden interior del alma" (Jung, 2013, p. 302). Si se utilizara un lenguaje religioso, se podría afirmar que la individuación ha de comprenderse como la realización de lo divino en lo humano.

La experiencia terapéutica analítica acumulada indica que, al tratarse de una conexión interior entre componentes de la personalidad, los símbolos en la individuación representan lo que ocurre en el proceso de reunificación a lo interno de la psique, mostrando la configuración del sí-mismo. El sentido de la vida para Jung, (en Jaffe, 1995), es la realización del sí-mismo.

El impulso del sí-mismo hacia su superación logra hacer de la vida una tarea de orden supremo. Esto no excluye la posibilidad de la derrota, sino integrar las experiencias y otorgarles un sentido vivificado, el cual es aportado por las figuras de lo inconsciente (Hernández-Mella, et al., 2015). En la medida que toda existencia se haya ligada a una carrera individual, se hace imperante reconocer su objetivo y la carga que aporta su destino a ella, apunta Jaffe (1995) al interpretar a Jung.

El sí-mismo resulta de la unión de la conciencia "o de la personalidad yoica" (Jung, 2013, p. 249) con lo inconsciente, en el proceso de individuación; es decir, se genera una personalidad nueva que contiene a ambos elementos. El proceso de individuación hace posible que el paciente se convierta 
en lo que propiamente es. "El camino individual necesita conocer las leyes propias del individuo; de lo contrario se extravía en las opiniones arbitrarias de la consciencia y se despega del suelo materno del instinto individual" (Jung, 2013, p. 15).

Un ser humano que no esté consciente de su destino como individuo es susceptible de perder su personalidad en la masa de personas con un comportamiento normalizado. El efecto que surge de ello es no sentirse responsable de lograr ningún cambio importante en beneficio propio ni de su comunidad. Incluso, de considerarse incapaz de ejercerlo (Jaffe, 1995).

Se genera una sensación de vacío existencial, la cual juega un papel importante en la etiología de la neurosis de estos tiempos. Es el sufrimiento humano que la psicoterapia intenta transformar por medio al proceso de individuación, que, al decir de Jaffe (1995) en coherencia con Jung, alienta el desarrollo de una unidad interior en torno a una imagen de Dios paradójica.

En la experiencia de Jung (2013) como psicoterapeuta, la curación no llega si no se recobra una visión religiosa, que en la interpretación junguiana corresponde al reconocimiento de la esencia númine que posee la realidad; es decir, de su energía y misterio profundos. Solo con esta visión se desarrolla una experiencia vital con sentido propio. La vida se vive, según Jung y expresado por Jaffe (1995), solo cuando el existir se convierte en una verdad espiritual.

De esa manera, Jung (2011) unió la brecha existente entre la ciencia y la religión, instaurando una base para un cuadro unitario del mundo. De ser un mundo que había excluido las verdades espirituales, limitándolas a ser nada más un acto de fe, el autor crea la oportunidad de hacerlas parte de los saberes aceptados. Esta puede considerarse la contribución de Jung (2011) más importante a la historia de la mente humana.
Cuanto más presente en la vida del individuo se tiene la cualidad espiritual del sí-mismo, más se amplía la conciencia por medio a la inclusión de contenidos psíquicos arcaicos que la equilibran. Esto trae consigo más arraigo en la realidad, que es en la propia tierra, en su cuerpo, y una mayor responsabilidad al vinculase a los seres más cercanos y queridos, y a su entorno (Jaffe, 1995).

La individuación, con la experiencia concomitante de una realidad religiosa, si bien viene a ser la más íntima de todas, no por eso se restringe a lo personal; también cumple una función en la vida colectiva del individuo, destaca Jaffe (1995) al recuperar a Jung. Este proceso de desarrollo humano consigue de la psique que se aprecie como un instrumento necesario para reorganizarse individualmente, lo mismo que para promover una reforma social y cultural.

En el proceso de desarrollo de nuestra vida, es importante apreciar que para Jung $(2012,2013)$ no somos sencillos espectadores ni víctimas de las tendencias de la época, sino también hacedores. Igualmente, Jaffe (1995) nos invita a reconocer que, para Jung, la historia del mundo surge, en última instancia, a partir de las realizaciones y potencialidades ocultas en los individuos. Las colectividades se constituyen de individuos y cada uno y una dan forma a la vida social, así como a la esfera política de la humanidad, pues solo en el individuo la vida puede cumplir su sentido.

\section{Referencias}

Abram, D. (1997). The Spell of the Sensuous: perception and language in a more-than-human world. New York: Vintage Book.

Camacho, R. (2020, 29 de abril). Beber del Espejismo (... o la alucinación que salva cuando hiere). Recuperado de https://www.facebook. com/ruben.camacho.5439/posts/3105394 446150310 . 
Coll, C. (2012). Jean Piaget. Impacto y vigencia de sus ideas. Grandes de la Educación. Recuperado de: https://www.researchgate.net/ publication/255878086_Jean_Piaget_Impacto_y_vigencia_de_sus_ideas

Freud, S. (1991). Psicoanálisis del Arte. Madrid: Alianza Editorial.

Freud, S. (2000). Lo Inconsciente. Obras Completas. Tomo XIV. Buenos Aires: Amorrortu.

Hernández-Mella, R., Liranzo-Soto, P., y Castillo, P. (2015). Las Diosas Sometidas. Encuentros afectivo-participativos y sus efectos en el self. Ciencia y Sociedad, 40(1), 133-170.

Hernández-Mella, R., y Pacheco-Salazar, B. (2017). La (pre)ocupación por el aprendizaje: desde la complejidad piagetiana al conocimiento situado. Ciencia y Educación, 1(1), 37-44.

Hernández-Mella, R., Liranzo-Soto, P., Jiménez-Soto, A., y Pacheco-Salazar, B. (2017). Encuentros Psico-Afectivos. Estrategia lúdica y creativa en favor de una experiencia escolar integral. Ciencia y Sociedad, 42(3): 69-83.

Hernández-Mella, R., D’Meza-Pérez, P., Ramírez-Jiménez, N., Morel-Camacho, J., Peña-Lantigua, L., y Olivier-Sterling, C. (2019). "Mírame a los Ojos": comprender el autismo desde quien lo vive. Ciencia y Sociedad, 44(2), 27-36.

Hernández-Mella, R., D’Meza-Pérez, P., Ramírez-Jiménez, N., Morel-Camacho, J., Peña-Lantigua, L., y Olivier-Sterling, C. (2020). El Arte y su Poder Transformador. Inconsciente, emociones y creación según la perspectiva junguiana. Ciencia y Sociedad, 45(1), 25-34.
Jaffe, A. (1995). El Mito del Sentido en la Obra de C. G. Jung. Madrid: Editorial S. A. Mirach

Jung, C. (1992). Formaciones de lo Inconsciente. Barcelona: Paidós. Psicología Profunda.

Jung, C. (1995). El Hombre y sus Símbolos. Barcelona: Paidós.

Jung, C. (2000). Lo Inconsciente. Buenos Aires: Losada, S. A.

Jung, C. (2011). Psicología y Religión. Barcelona: Paidós.

Jung, C. (2012). Introduction to Jungian Psychology. New Jersey: Princeton University Press.

Jung, C. (2013). La Práctica de la Psicoterapia. Obras Completas. Volumen 16. Madrid: Editorial Trotta.

Karpov, Y. (2006). The Neo-vygoskian Approach to Child Development. New York: Cambridge University Press.

Piaget, J. (1975). Problemas de Psicología Genética. Barcelona: Ariel.

Piaget, J. (1986). Seis Estudios de Psicología. Barcelona: Barral.

Piaget, J. y García, R. (1984). Psicogénesis e Historia de la Ciencia. México Capital: Siglo XXI Editores.

Quasimodo, S. (2007). Poesía Completa. Orense: Editorial Linteo.

Vygotsky, L. S. (1979): El Desarrollo de los Procesos Psicológicos Superiores. Barcelona: Grijalbo.

Vygotsky, S. L. (2010). Teoría de las Emociones. Estudio histórico-psicológico. Madrid: Akal. 


\section{Datos de filiación}

Rocío Hernández Mella. Profesora-investigadora del Área de Ciencias Sociales y Humanidades del Instituto Tecnológico de Santo Domingo, INTEC. Doctora en Psicología Social; maestría en Planificación y Administración de la Educación; especialización en Psicología Educativa y licenciatura en Psicología. Consultora en Psicología y Educación para OEI-República Dominicana y el MINERD; coordinadora Educativa del Centro Jung Santo Domingo y vicepresidenta de la Fundación Tonucci: Educando para la Diversidad.

Josefina Gómez Mena. Es investigadora del centro Jung Santo Domingo, CJSD. República Dominicana. Sus líneas de investigación se centran en Biología: Malacología, Acuacultura, Gestión Ambiental Junguiana y Ecopsicología.

Yolanda Santos Batista. Es investigadora del Centro Jung Santo Domingo, CJSD. República Dominicana. Sus líneas de investigación se centran en Psicología Junguiana: Mito Personal; Biodanza: psicoterapia corporal. 